\title{
Pricing Unbundled Network Elements and the FCC's TELRIC Rule: Economic and Modeling Issues
}

\author{
TIMOTHY J. TARDIFF*
}

National Economic Research Associates

\begin{abstract}
This paper addresses the fundamental question of what costs and prices would look like under competitive conditions and how close the FCC's total element long-run incremental cost (TELRIC) pricing rules allow one to approximate such competitive outcomes. We consider: what types of firms would enter in competitive network industries, what effect would new entry have on the asset values and prices of incumbent firms, and what impact would competition have on (1) the types and vintages of capital equipment, (2) prices for that equipment, and (3) conditions in the operating environment? The paper concludes by highlighting alternative pricing proposals offered by contending parties and identifying the major drivers that explain what have proven to be large differences among competing proposals.
\end{abstract}

\section{Introduction}

The Telecommunications Act of 1996 requires that incumbent local exchange carriers (ILECs) provide certain elements of their networks to competitive local exchange carriers (CLECs). Prominent among these elements are the local loop (the connection between a subscriber and a telephone company's local switch) and, perhaps to a lesser extent, the functions produced by the switch itself. The Telecommunication Act requires that these network elements be priced at cost, with the possible addition of a reasonable profit. ${ }^{1}$ The Federal Communications Commission (1996) issued rules for determining these prices. ${ }^{2}$ The FCC's rules were based on a model of a hypothetical carrier that places switches in the

\footnotetext{
* Mailing address: National Economic Research Associates, One Main Street, Cambridge, MA 02142, USA. E-mail address: timothy.tardiff@nera.com. An earlier version of this paper was presented at the Advanced Workshop in Regulation and Competition, 21st Annual Conference, Newport, Rhode Island, May 23, 2002. This paper has benefited from my collaboration with Professor Howard Shelanski in our joint appearances as witnesses on behalf of Verizon in unbundled elements pricing proceedings in Virginia and Pennsylvania and from the discussions with and comments of Professor Dennis Weisman.

$1 \S 252(\mathrm{~d})(1)$.

2 These pricing rules, along with numerous other parts of the FCC's interconnection rules, were almost immediately challenged by ILECs and a number of state regulators. In July 1997, the $8^{\text {th }}$ Circuit Court of Appeals overturned the FCC's pricing rules on the grounds that the states, rather than the FCC, had jurisdiction over pricing. In January 1999, the Supreme Court upheld the FCC's authority to establish pricing rules (which are implemented by the states), but did not then rule on the merits of the rules themselves.
} 
ILEC's existing switch locations and then builds a new network to customer locations. ${ }^{3}$ The FCC's objective in establishing this rule was unexceptionable: to determine the "incremental costs that incumbents actually expect to incur in making network elements available to new entrants" and to adopt a pricing methodology that "best replicates, to the extent possible, the conditions in a competitive market."4

While parties have not necessarily disagreed with the FCC's objectives, ${ }^{5}$ the rules themselves have been extremely controversial. In fact, in July 2000, the $8^{\text {th }}$ Circuit Court of Appeals (2000) vacated the rules, noting that:

It is the cost of providing its existing facilities and equipment either through interconnection or by providing the specifically requested existing network elements that the competitor will in fact obtain for use that must be the basis for the charges. The new entrant competitor, in effect, piggybacks on the ILEC's existing facilities and equipment. It is the cost to the ILEC of providing that ride on those facilities that the statute permits the ILEC to recoup...At bottom, however, Congress has made it clear that it is the cost of providing the actual facilities and equipment that will be used by the competitor (and not some state of the art presently available technology ideally configured but neither deployed by the ILEC nor to be used by the competitor) which must be ascertained and determined. (p. 8)

The FCC, AT\&T, and WorldCom quickly appealed that decision. The Supreme Court agreed to hear parts of the appeal during 2001 and upheld the FCC's rule (thus overturning the lower court's decision) on May 13, 2002. ${ }^{6}$ While the Court offered substantive reasons for its decision (which Weisman (2002) evaluates in detail), the basis for the decision seems to be the traditional deference to expert agencies when the interpretation of a law may be ambiguous. The decision (Supreme Court, 2002) concluded with the following:

Whether the FCC picked the best way to set rates is the stuff of debates for economists and regulators... The job of judges is to ask whether the Commission made choices reasonably...The FCC's pricing and additional combination rules survive that scrutiny.

\footnotetext{
${ }^{3}$ Specifically, the FCC added various rules to Title 47 of the Code of Federal Regulations. The rule which deals with forward-looking cost is 47 CFR $§ 51.505$, which states (among other things) that: "The total element long-run incremental cost of an element should be measured based on the use of the most efficient telecommunications technology currently available and the lowest cost network configuration, given the existing location of the incumbent LEC's wire centers."

4 FCC (1996, ๆs 685 and 679).

5 While there is general agreement among economists that regulated prices should emulate those that competition would produce, the question of what the relevant competitive standard is remains. The cost models proposed by CLECs hold perfect competition (or at least perfect contestability) as the proper standard. Others, e.g., Lehman and Weisman (2000: 52-55), have argued that a Schumpeterian perspective is closer to the proper standard. Under this standard, prices would be based on the least efficient firm that survives in the industry, rather than a hypothetical most efficient firm. (See also McDermott and Peterson (2001))

${ }^{6}$ In addition to vacating the part of the pricing rule dealing with the use of a hypothetical network, the $8^{\text {th }}$ Circuit also vacated rules, including: (1) the requirement the ILECs combine elements that are not currently combined; (2) the requirement that ILECs offer elements of superior quality, upon request by a CLEC; (3) the rule for establishing wholesale prices; (4) the rules for establishing rural exemptions to interconnection rules. In addition to the pricing rule for unbundled elements, the Supreme Court reviewed and upheld the rule requiring combinations. All the other rules in the list above were not granted review, implying that they have been vacated. In addition, the $8^{\text {th }}$ Circuit upheld a number of other rules. For purposes of this discussion, the most prominent of these was the requirement that the prices for interconnection and network elements be based on forward-looking, rather than historical book costs. A consortium of ILECs appealed the $8^{\text {th }}$ Circuit Court's ruling on historical costs and the Supreme Court granted a review of that issue, ultimately upholding the lower court's ruling.
} 
Despite the fact that the status of the FCC's rules had been uncertain for almost two years, a number of states conducted reviews of UNE prices during that period, ${ }^{7}$ with parties agreeing to abide by the challenged rules. At the same time, the major parties - the ILECs, the FCC, and the CLECs - weighed in at the Supreme Court with their interpretations of what economic costs in a competitive market would look like. Perhaps the most prominent of these cases was the Virginia proceeding, where the FCC itself presided on behalf of the state of Virginia. ${ }^{8}$ Finally, just two days after the Supreme Court's decision, ${ }^{9}$ the FCC (2002a) interpreted its newly affirmed TELRIC rules when it approved the application of BellSouth to offer interLATA long-distance service in Georgia and Louisiana. ${ }^{10}$ In its discussion of compliance with TELRIC rules, the FCC dealt with a number of the contentions discussed in this paper, which is described in more detail below.

This paper focuses on the economic debates over whether and how the FCC's rules for pricing unbundled network elements can accomplish their stated objective: basing those prices on the economic value of the ILEC's network assets that the CLEC uses when it leases unbundled elements. That is, although the rules call for calculating costs based on a hypothetical network that departs from the ILEC's actual network in substantial ways, the FCC and the other proponents maintain that the costs produced from a model of a hypothetical network nevertheless are the same as the economic costs the ILEC incurs when it offers its UNEs using its actual network. Key issues have focused on the degree to which new entrants in competitive network industries can realistically install and update long-lived capital assets consistent with the hypothetical models. That is, do such models properly depict the operating environments of competitive firms or are there constraints in real-world operating environments that the hypothetical construct fails to capture?

The paper is organised as follows. In the next section, the competing economic positions are described and a framework for assessing their major differences is presented. Section 3 presents specific costs measures that have been produced by the competing ILEC and CLEC economic perspectives and identifies factors that account for the large differences in these measures. Section 4 concludes the paper.

\footnotetext{
7 I have appeared as a witness on behalf of Verizon in four states: Virginia, Maryland, Massachusetts, and Pennsylvania. In at least one other state - New York - despite the fact that the Supreme Court review arose during the course of the proceeding, the Commission proceeded to establish new rates. See New York Public Service Commission (2002).

${ }^{8}$ Among the state proceedings in which I participated, the economic issues discussed in this paper had their most thorough airing in Virginia. The characterisation of ILEC and CLEC positions is primarily based on the Virginia experience; it could well be the case that issues and/or positions of major parties differ somewhat in other jurisdictions.

${ }^{9}$ It is also noteworthy that on May 24, 2002, less than two weeks after the Supreme Court's Decision on TELRIC, the District of Columbia Circuit Court of Appeals (2002) overturned the FCC's order that determined which network elements must be unbundled. That is, while its pricing rules have been legally validated, there is a new question as to which elements will be subject to the rules.

${ }^{10}$ Under $\S 271$ of the Telecommunications Act, the FCC will approve an application to offer long-distance if the applicant has met a "check list" of items that demonstrate that local exchange markets are open to competition. Pricing unbundled elements in conformance with TELRIC is a key item on the checklist.
} 


\section{Measuring the costs of local exchange networks: Competing economic perspectives}

The primary theoretical disagreement among economists representing contending parties in the most recent unbundled network element (UNE) pricing proceedings has been over the nature of forward-looking economic costs. Proponents of the CLECs have argued that forward-looking costs in competitive markets match those of a new entrant that employs (1) new equipment, (2) purchased at current prices, (3) for the entire volume of demand the incumbent local exchange carrier serves. The only constraint acknowledged in this position is that the existing locations of the ILEC's switches (wirecenters) are assumed in estimating forward-looking costs. ${ }^{11}$ The ILEC's position, on the other hand, focuses on the forward-looking costs that incumbents' could actually expect to incur when offering UNEs to competitors, ${ }^{12}$ which in turn requires recognition of the constraints that firms that operate large capital-intensive networks face.

Although the competing economic positions end up with very different views of what forward-looking costs look like, they share a common starting point. In particular, parties agree that forward-looking costs are the result of decisions that answer the following question: when is it more economic (lower cost) to replace existing assets (e.g., a switch) with newer equipment. And all parties agree on the answer: when the operating cost savings (perhaps enhanced by incremental profits from new services) from selecting the new equipment exceed the net investment for the new equipment. ${ }^{13}$ Further, parties tend to agree that it may be perfectly rational for a going concern to make such investment decisions sequentially, taking into account the possible need for any new equipment to be compatible with the rest of the equipment in the network. Finally, parties agree as an economic matter that the economic costs of completely replacing an ongoing network with new equipment are an upper bound on a firm's actual forward-looking costs.

Despite the common point-of-departure and agreement on a number of steps along the way, the competing interests arrive at different theoretical end-points (CLEC proponents arguing that economic costs equal those of an unfettered new entrant, while ILEC supporters argue that the proper costs are determined by considering the sequential business decisions that all seem to concede that a going concern would make) and quantitative outcomes (with the putative upper bound of complete replacement being lower than the costs calculated from explicit consideration of the business decisions actually

\footnotetext{
$11 \S 51.505(\mathrm{~b})(1)$. In debating the implications of this rule for the conduct of cost studies, while all parties accept that the network to be considered starts with existing wirecenter locations, they fundamentally disagree as to whether "most efficient technology" and "lowest cost network configuration" can recognise the constraints imposed on any business that operates a capital-intensive network in which assets have long lives and in which technological progress can be rapid, but (along with demand for services) uncertain.

${ }^{12}$ The FCC's discussion that defines the rationale for its TELRIC study rules states that the benchmark given in the rule "most closely represents the incremental costs that incumbents actually expect to incur in making network elements available to new entrants." (Local Competition Rules, - 685). Given that the FCC's objective does not differ from the ILECs' position that a cost study should measure their costs, the issue becomes on of whether a particular interpretation of the TELRIC cost study rules will actually satisfy the objective of attaining measures of the ILECs' actual costs.

13 The net investment is the difference between the purchase price of the new equipment plus any transactions costs incurred in using that equipment (e.g., removal costs, extra costs from the premature retirement of other equipment that is incompatible with the new equipment, etc.) and the resale value (if any) of the old equipment.
} 
made). ${ }^{14}$ Some, but certainly not all, of the differences are undoubtedly attributable to particular inputs, e.g., CLEC cost studies typically propose lower prices for items such as telephone poles than do ILEC studies.

To shed light on why the alternative viewpoints have reached such different end-points despite sharing a common starting point, it is useful to (1) identify the conditions under which costs in an industry would match those of a brand-new entrant and (2) assess the extent to which local exchange carriers depart from those conditions. The brand-new entrant model effectively treats each component of a complicated network as a separate service, provided in isolation from other services. For each such service, there is (1) sufficient volume and/or sufficiently short asset lives so that a new firm could enter at an efficient scale and (2) transaction costs (e.g., installing new equipment and/or selling old equipment on secondary markets, ${ }^{15}$ compatibility with other components of the network, etc.) are small or non-existent. Under these conditions, (1) the value of the old assets would be completely determined by the cost of deploying new assets, (2) the prices charged by incumbent firms could be no higher than the forward-looking costs of the brand-new entrant, and (3) as a result, productivity growth in the industry would be completely determined by the cost trajectory of new equipment. ${ }^{16}$

Departures from the conditions under which it is reasonable to assume that a brand-new entrant determines the industry's forward-looking cost would make that approximation less and less accurate. In particular, when volumes are insufficient to make immediate, ubiquitous entry economic, assets have long lives, and/or there are significant transaction costs in replacing old with new equipment, then basing costs on those of a counter-factual, unfettered new entrant ${ }^{17}$ will be both inaccurate and understate costs. While any real-world firm in that industry would face transaction costs typical of that industry as it adjusted its network over time, the cost model effectively assumes a different industry where those costs do not exist.

A formal representation of a replacement decision illustrates these issues: ${ }^{18}$

Replace if:

$\left(\right.$ Revenue $_{\text {new }}-$ Revenue $\left._{\text {old }}\right)+\left(\right.$ Operating Cost old $_{\text {o }}$-Operating Cost $\left.t_{\text {new }}\right)>$

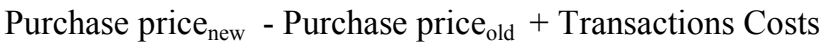

This representation shows that replacement is more likely when (1) the operating cash flow (incremental revenues plus operating costs savings) are larger, (2) the purchase price

\footnotetext{
14 The correct costs would also reflect the constraints under which the incumbent operates, including carrierof-last resort obligations and the fact that its network was not designed a priori to serve wholesale and retail.

15 Emmerson (1999) discusses the likelihood that such secondary markets might be weak or even nonexistent and the effect of such "market failures" on proper measurement of economic costs.

${ }^{16}$ One approach in the theoretical literature is to take ubiquitous entry by a new provider as a given and to then ask how the prices of incumbents would respond to the prospect of such entry (See, for example, Hausman (1997); Crew and Kleindorfer (1992); Salinger (1999); and Mandy (2000)). These analyses show that even a new entrant with entirely new equipment would not base prices on the type of levelised costs produced by the models that have emerged from the FCC's rules. Instead, prices would tend to be higher in the early years of an asset's lifetime and decline in anticipation of technological progress in the industry.

17 Because conditions in the industry make ubiquitous entry uneconomic, any real firm would build capacity over time and therefore incur the same type of transaction costs in the future as it made incremental decisions to expand its network.

${ }^{18}$ In the formula below, the operating cash flow should be interpreted as a present value over several years.
} 
of the old equipment (i.e., whatever the resale value on the secondary market is) is higher, and (3) transaction costs (e.g., removal costs, costs associated with incompatibilities with other parts of the network, etc.) are lower.

In particular, when there are no transaction costs and there are complete secondary markets for used network equipment, the purchase price of the old equipment is the following:

"Theoretical" purchase price ${ }_{\text {old }}=$ Purchase price $_{\text {new }}-\left[\left(\right.\right.$ Revenue $_{\text {new }}-$ Revenue $\left._{\text {old }}\right)+\left(\right.$ Operating $_{\text {Cost }}$ old

- Operating Cost $\left.\left._{\text {new }}\right)\right]$

That is, the amount that an old asset can command in a secondary market is simply the purchase price of a new asset, less the difference in operating cash flow between the old and new assets. To the extent that such markets are less than perfect or non-existent, e.g., network equipment is effectively sunk and/or not fungible, the purchase price of the old assets will be lower, and as a result replacement with a new asset becomes less likely. ${ }^{19}$ This effect can be further explored by expressing the actual resale price in terms of the price that would prevail in the hypothetical instant replacement world as follows:

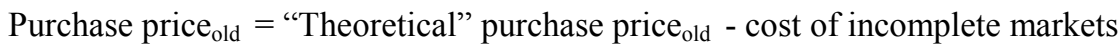

Inserting this expression into the original decision rule produces the following:

Replace if:

$\left(\right.$ Revenue $_{\text {new }}-$ Revenue $\left._{\text {old }}\right)+\left(\right.$ Operating Cost old $_{\text {- Operating Cost }}$ new $)>$

Purchase price $_{\text {new }}$ - "Theoretical" purchase price old + cost of incomplete markets + Transactions Costs

This restatement shows that there are two types of costs that are inadequately considered and/or ignored in the hypothetical instantaneous replacement models: (1) the cost to a firm from the fact that its old assets are less valuable because of incomplete secondary markets and (2) any transaction costs that may be present. To the extent that such costs are typical and ongoing costs for firms in the industry, any model that assumes they do not exist will understate the economic costs of firms in the industry and prices based on such models will be uneconomically low. In other words, the costs of full replacement serve as an upper bound for economic costs only if all economic costs that firms typically face are considered. ${ }^{20}$

Having established that the ubiquitous replacement assumption excludes certain costs faced by firms in the industry, the question of the magnitude of such costs arise. There have been a number of previous approaches to addressing this issue. For example, as described earlier, a number of analyses have effectively accepted the instant entry hypothesis and then posed the question of how much faster a firm facing the prospects of such entry would need to recover their investments in light of the technological progress and demand uncertainty

\footnotetext{
${ }^{19}$ At first glance, the idea that an asset which is worth less (i.e., has a lower resale value) is more likely to be retained may seem counterintuitive. However, there are common examples of this phenomenon, e.g., increasing the trade-in value of an old car makes a purchase of a new car more attractive. Alternatively, the lower the resale value, the lower the opportunity cost of holding the asset and hence the more likely the asset will be retained, ceteris paribus.

${ }^{20}$ Shelanski (2001) explains how the availability of new technology constrains the value of existing assets. In the context of the current discussion, the presence of costs imposed by incomplete markets and transaction costs make the constraint less binding.
} 
facing the telecommunications industry. ${ }^{21}$ Lehman and Weisman have taken a different approach. $^{22}$ Rather than explicitly quantifying the magnitude of costs excluded by heroic assumptions of ubiquitous replacement, they pose the question of how much such hypothetical costs differ from embedded costs - the actual operating costs to run a network of varying vintages of equipment, valued at the prices paid for equipment when purchased. $^{23}$ Based on simulations of embedded and hypothetical costs over a long-run period, they produce ranges within which cost differences should fall. The ranges they produce are generally smaller than the differences between embedded costs and rates actually adopted by regulators, suggesting that other factors, e.g., inputs such as equipment prices, cost of capital, and depreciation rates, etc., explain the generally lower levels of the adopted UNE rates.

Another rationale for using embedded costs as a benchmark for the results of a cost study is the following analogy. Suppose businesses competed by acquiring their inputs under long-term leases and suppose that current volumes and expected growth were such that any individual lease accounted for only a fraction of the total volume of a particular firm. The costs for firms in the industry would be the payments for the portfolio of leases that they held, and if the market for the output of these firms were competitive (and there were no secondary markets for the leases), then output prices would tend to be an average of the input costs from the portfolio of leases held by the competing firms. Because embedded costs are conceptually similar to an average of such lease payments, i.e., the capacity available from equipment of a particular vintage is similar to the volume available from a particular lease, this outcome would approximate prices based on embedded costs.

The proposition that the costs of real companies might be greater than those produced by hypothetical ubiquitous replacement models (and the explanation of why this should be the case) is reminiscent of the observation that certain technological innovations, such as computers recently, and dynamos at the beginning of the $20^{\text {th }}$ century, have taken longer than expected to be widely adopted and, therefore, make a significant impact on productivity. In particular, the analyses of these historical phenomena provide insight into why the costs of real companies in network industries may not be explained very well by hypothetical models that assume the full deployment of the latest technology. For example, David (1990) enumerates a number of reasons why the advent of the dynamo did not result in immediate widespread adoption and concomitant productivity gains, including (1) the durability of existing equipment and (2) the fact that adoption was greatest in industries

\footnotetext{
${ }^{21}$ This issue is discussed in greater detail in Tardiff (2001).

${ }^{22}$ Lehman and Weisman (2000: Chapter 6). One of the reasons Lehman and Weisman offer their comparison between costs based on hypothetical cost models and embedded costs is the general lack of external measures against which to validate the results of cost models. These authors' concerns about validating model results call to mind a statement of Maurice Allais (1997) in his 1988 Nobel Lecture:
}

The model and the theory it represents must be accepted, at least temporarily, or rejected depending on the agreement or disagreement between observed data and the hypotheses and implications of the model. When neither the hypotheses nor the implications of a theory can be confronted with the real world, that theory is devoid of any scientific interest. [emphasis in original]

${ }^{23}$ Embedded capital costs include depreciation of the embedded plant, plus a return on the undepreciated value of that plant. 
with the highest growth (i.e., demand was such to make rapid deployment economic). ${ }^{24}$ Without such prerequisites for rapid adoption, firms in an industry will be unlikely to have fully deployed the latest and least cost technology at any snapshot in time, and consequently, the costs of a hypothetical firm assumed (contrary to fact) to have deployed such technology system-wide will not describe costs and prices in the industry. ${ }^{25}$

\section{Measuring the costs of local exchange networks: Implementation issues}

The competing conceptions of economic costs differ not only in theory, but have contributed at least in part to large differences in recommended prices for UNEs. For example, in the recent Virginia arbitration, Verizon - the ILEC - proposed a loop price of about \$22, while AT\&T and WorldCom advocated a loop cost of about $\$ 6.50 .^{26}$

Before presenting some of the major economic assumptions that explain the difference in the cost proposals, it is useful to explain that AT\&T/WorldCom's proposal was based on their modification of the FCC's Synthesis Model, which has been used to provide forwardlooking costs of basic service for the federal universal service program since $2000 .{ }^{27}$ The parties modified the FCC's Model as follows: (1) assigned indirect costs (e.g., corporate overheads) to specific UNEs, (2) increased the line counts used to calculate costs, (3) made certain calculation changes, mostly intended to correct alleged errors in the FCC's model,

\footnotetext{
${ }^{24}$ These conditions are among the reasons why firms possess scale economies. In other words, failure to recognise such characteristics when estimating the costs that would prevail under competition ignores the conditions that motivated network unbundling in the first place.

${ }^{25}$ Proponents of ubiquitous replacement models have argued that the assumption that any firm actually deploys the latest technology system-wide is a caricature of their theory. For example, in its brief to the Supreme Court, the FCC (2001) stated:
}

The incumbents assert that TELRIC assumes that a carrier would scrap its existing network and rebuild a new, more efficient one every time an advance in technology occurs. TELRIC assumes no such thing. TELRIC instead rests on the rational economic assumption that, as new, more efficient equipment becomes available, the value of older, less efficient equipment will be affected.

That is, while agreeing that ILECs (and probably no real firms for that matter) do not actually build networks in this fashion, they nonetheless maintain that prices in the industry behave as if firms did this. However, if that description were accurate, one would expect to see the productivity performance in industries with durable assets reflect such pricing behavior. David's explanations suggest that firms in such industries neither literally replace assets nor price their outputs consistent with ubiquitous replacement models. In addition, while the proposition that the value of older equipment will be affected by the availability of newer equipment is theoretically sound, the practical issue is whether the magnitude of that effect is (or can be) accurately represented in a TELRIC study.

${ }^{26}$ While the precise costs are not identical, the general pattern in Virginia appeared in other states with recent UNE cases (Maryland, Massachusetts, and Pennsylvania) as well. The following alternative loop costs for Virginia provide context for comparing the loop costs proposed by the competing parties: the current rate is $\$ 13.76$, the FCC's universal service model produces a loop cost of $\$ 19.16$, and data compiled by NECA shows an embedded loop cost of $\$ 19.03$. The fact that Verizon Virginia has been operating under price cap regulation, which is designed to provide incentives to operate efficiently, further calls into question the large difference between AT\&T/WorldCom's proposed rates (purportedly reflecting an "efficient firm") and current costs. (See Kahn, Tardiff, and Weisman, 1999: 330-332.)

${ }^{27}$ See Federal Communications Commission (1998 and 1999). 
and (4) changed a number of inputs, e.g., the proportions of outside plant assumed to be on poles versus underground. ${ }^{28}$

The competing economic perspectives manifest themselves in a number of specific input choices. The most prominent of these have been the financial parameters of cost of capital and depreciation rates. As discussed earlier, if the assumption of ubiquitous replacement describes how firms enter and respond to entry in competitive markets, the theoretical literature cited earlier demonstrates they would have to recover their investments much quicker than regulatory rates of depreciation and cost of capital permit. In fact, in defending its rules before the Supreme Court, the FCC (2001, pp. 10-11) suggested that the dispute between it and the ILECs boiled down to the issue of proper financial parameters and that its rules were flexible enough to accommodate the correct values. While this proposition may have some theoretical validity, it seems it would be extremely difficult to carry out in practice. In particular, depreciation calculations, even when done properly, have focused on the changes in the initial purchase prices of network assets. In contrast, to meet the FCC's objective, the treatment of depreciation would have to be broadened to include any cost difference between a real-world firm functioning efficiently in a network industry and the costs captured in a ubiquitous replacement model. Rather than attempt to capture these in depreciation rates, it may well be more accurate to identify such costs directly and design the forward-looking model to explicitly include them.

The identification of some of these costs emerges from comparing the fundamental assumptions used to represent network assets under the competing approaches. The ubiquitous replacement models assume that a new entrant would deploy facilities to "efficiently" accommodate a known level of demand, more or less precisely located. In building a network under such favorable circumstances, the hypothetical entrant would enjoy economies of the following sort: (1) it could directly route facilities from its wirecenter buildings to customer locations, while a carrier that built sequentially as demand materialized over time might have less direct routes, ${ }^{29}$ (2) because demand is known with a high degree of certainty, lower levels of spare capacity are needed for the flexibility that real firms must have to accommodate growth and fluctuations in demand, ${ }^{30}$ (3) there would be greater opportunity to share structure, such as utility poles and underground structures with other carriers, (4) there would be economies in mass deployment of facilities such as telephone poles, because work crews could be deployed more efficiently than real telephone companies are able to do, (5) because all equipment is purchased new to serve the entirety of demand at a point in time, for equipment such as switching for which manufactures offer deep discounts for initial purchases (a razor/razor blade pricing strategy), all equipment would be purchased at the deeper initial discount, ${ }^{31}$ and (6) the

\footnotetext{
${ }^{28}$ Pitkin (2001).

29 In addition, as a practical matter, the models used to depict the routes of facilities are typically not sophisticated enough to represent real-world obstacles that would increase costs. Indeed, because real-world routes already reflect accommodation to such obstacles, they could well be more efficient than hypothetical routes chosen by some "optimization" routine. Interestingly, the FCC (2002a) approved the use of a properly constructed loop sample (which would reflect an ILEC existing routes) as being consistent with TELRIC.

${ }^{30}$ While CLECs have argued for lower amounts of spare capacity and the FCC's own universal service cost model (described above) produces low levels of spare capacity, the FCC (2002a) rejected the CLEC's claim that larger amounts of spare capacity necessarily violate TELRIC rules.

31 The FCC has been ambivalent on this issue. In particular, while its universal service model, upon which AT\&T/WorldCom rely for switching costs, effectively assumes all new switches, purchased at the new switch
} 
network would have the latest vintages of technology deployed ubiquitously throughout the network, even in cases where compatibility among various network components would make such ubiquitous deployment uneconomic for any real firm. ${ }^{32}$

In addition to differences resulting from competing modeling philosophies, AT\&T/WorldCom argued that (1) lines counts have been growing rapidly and should continue to grow in the near future and (2) that this growth will produce scale economies, primarily in the form of more intense use of support structures, such as poles. ${ }^{33}$ These assumptions produce a large increase in lines over current levels (on the order of 50 percent or more), which is at best speculative ${ }^{34}$ and most likely highly unrepresentative of the scale economies actually attainable by real-world carriers. First, the large majority of the line growth measured and projected by AT\&T/WorldCom was in high capacity facilities that typically do not coincide physically with ordinary lines. However, the Synthesis Model depicts these lines as ordinary loops. Second, the Model has treated growth in lines effectively as additional lines at existing locations, while in actuality some of this growth would be telephone lines to new locations. ${ }^{35}$

\begin{tabular}{|l|l|l|l|}
\hline Year & Lines (million) & Loop Cost & Distribution Areas \\
\hline 1996 & 3.46 & $\$ 9.74$ & 3,429 \\
\hline 2002 (revised) & 5.68 & $\$ 6.48$ & 4,807 \\
\hline 2002 (original) & 6.67 & $\$ 5.92$ & 5,557 \\
\hline 2004 & 7.96 & $\$ 5.29$ & 6,172 \\
\hline
\end{tabular}

Table 1: The Effect of Line Growth on Loop Costs

discount, it advised the Supreme Court that its rules do not require this assumption. (FCC, 2001, p. 9, fn. 7) and even more recently, affirmed that position when it rejected the CLECs' arguments that the BellSouth costs were invalid because all new switches were not assumed (FCC, 2002a). The assumption of universal availability of a new switch discount has a large impact on switching costs. For example, while AT\&T/WorldCom's study produced a switch investment of about $\$ 112$ per line, Verizon's study, which uses the discount it has received on recent purchases, produces an investment of about $\$ 285$ per line.

32 The most prominent example of this issue is the type of digital loop carrier (DLC) equipment - the electronic equipment used with fiber-fed loop facilities - assumed in competing cost studies. CLEC cost studies typically assume 100 percent of "next generation" GR-303 electronics for fiber-fed loops. In contrast, recent ILEC studies have assumed little to no such equipment, but instead have assumed predominant use of earlier vintages (TR-08 and universal DLC) - "current generation"). The rationales for the ILEC's assumption include the propositions that (1) incompatibilities with existing switches would make immediate full-scale deployment uneconomic, (2) there has yet to be a commercially available solution that allows GR-303 to provide individual unbundled loops, and (3) the "next generation" may prove to be a technology that never enjoys wide-scale deployment. Again, the FCC's (2002a) evaluation of costs in the BellSouth 271 proceeding appeared to recognize some of the practical issues in deploying "next generation" technology.

${ }^{33}$ For example, bigger cables, serving more lines could be placed on the same poles, thus reducing the perline cost of poles.

34 In fact, the upward trend in lines through 2000 that was the basis for the projections did not even persist through 2001. ILECs overall actually lost lines to the point where there were fewer lines at the end of 2001 than there were three years earlier. (FCC, 2002b: Table 8.1)

35 This effect is the result of AT\&T/WorldCom's (as well as the FCC when it applies its model to calculate universal service costs) updating line counts, but the number of customers, which are fixed at their 1997 locations and levels. 
It turns out that the line count assumptions were the single biggest explanation of AT\&T/WorldCom's low loop rates. The importance of line counts can be illustrated by examining the results of several line count scenarios AT\&T/WorldCom presented during the course of the Virginia proceeding to validate their assertion of scale economies. Table 1 presents these results.

According to these scenarios, the projected line growth between 1996 and 2004 would have the effect of reducing loop costs almost in half. This would be accomplished not only as the result of more intense use of support structures, but also by assuming that a latter-day "efficient carrier" would have completely different routes than an earlier "efficient carrier." This latter feature is illustrated by the fact that the Model divides the overall service territory into approximately twice the number of distribution areas, which if valid would suggest that "efficient" routes soon become obsolete, because a newer entrant could more accurately target its facilities. ${ }^{36}$

In contrast to the large reduction in loop costs generated by increased line counts for a hypothetical carrier, data for Verizon Virginia's actual network reveal no such economies. Of course, unlike the succession of hypothetical carriers represented in Table 1, Verizon cannot accommodate growth by ignoring expansion of its service territory, placing entirely new cables and possibly support structures when volumes expand, and completely reconfiguring its route structure. Table 2 presents the most recent line counts and embedded loop costs compiled by the National Exchange Carrier Association (NECA.) ${ }^{37}$

\begin{tabular}{|l|l|l|}
\hline Year & Lines (million) & Loop Cost \\
\hline 1994 & 2.92 & $\$ 19.60$ \\
\hline 1995 & 3.05 & $\$ 18.97$ \\
\hline 1996 & 3.17 & $\$ 18.42$ \\
\hline 1997 & 3.33 & $\$ 18.85$ \\
\hline 1998 & 3.47 & $\$ 18.77$ \\
\hline 1999 & 3.63 & $\$ 19.03$ \\
\hline
\end{tabular}

Table 2: Lines and Embedded Loop Costs for Verizon Virginia

\footnotetext{
36 Telephone networks consist of distribution areas of several hundred lines. Each location in a distribution area is connected to a central facility (serving area interface) within the area. From that point, either copper or fiber cable connects the distribution area to its serving wirecenter.

37 Before 2000, these costs were used to determine high cost funding for all LECs. Although the FCC's Synthesis Model has superceded these costs for larger LECs, they are still used for the smaller LECs (which receive the bulk of federal high cost funds).
} 
Table 2 clearly shows that Verizon Virginia has not enjoyed the scale economies that AT\&T/WorldCom's Model would suggest. Not only has its line growth been much lower (almost 25 percent growth in lines over 5 years), ${ }^{38}$ loop costs did not change appreciably as a result of this growth.

While the use of higher line counts and the resulting "scale economies" appear to be the major factor explaining AT\&T/WorldCom's low loop costs, their model employed several other inputs that had the effect of producing low loop costs as well. The relative impacts of these changes can be seen by comparing the loop cost produced by the FCC's application of its Model for universal service purposes in 2000 with the costs produced by AT\&T/WorldCom's modified model. ${ }^{39}$ These other changes included (1) financial parameters (cost of capital and depreciation rates); (2) other inputs, primarily (a) an acrossthe-board 10 percent reduction in distance in the distribution part of the loop plant, (b) the assumption that less of the most expensive support structure (underground) can be deployed by an "efficient" carrier, (c) more sharing of support structures, and (d) lower costs for the electronics used with fiber-fed loops; and (3) AT\&T/WorldCom's modifications to the Model's calculations. Table 3 shows the contribution of each type of input difference in reducing loop costs.

\begin{tabular}{|l|l|l|l|}
\hline & \multicolumn{1}{|c|}{ Model } & Direct Loop Costs & \% of Total Difference \\
\hline 1 & FCC Model & $\$ 9.82$ & $45 \%$ \\
\hline 2 & $\begin{array}{l}\text { FCC Model with } \\
\text { AT\&T/WorldCom's Line } \\
\text { Counts }\end{array}$ & $\$ 7.47$ & $\begin{array}{l}\text { Line 2 plus } \\
\text { AT\&T/WorldCom's } \\
\text { Financials }\end{array}$ \\
\hline 4 & $\begin{array}{l}\text { FCC Model with all } \\
\text { AT\&T/WorldCom's } \\
\text { Inputs }\end{array}$ & $\$ 5.14$ & $31 \%$ \\
\hline 5 & $\begin{array}{l}\text { AT\&T/WorldCom's } \\
\text { MSM }\end{array}$ & $\$ 4.63$ & $10 \%$ \\
\hline
\end{tabular}

Table 3: Impact of Input Changes on Loop Cost Estimates

The table shows that all of AT\&T/World/Com's changes reduce direct loop costs by $\$ 5.19$ (\$9.82 - \$4.63), or 53 percent. The higher line counts alone explain 45 percent of the total cost reduction.40 Contrary to the suggestion from theory that the ubiquitous replacement assumption implies high rates for depreciation and cost of capital,

\footnotetext{
38 The lines represented in the NECA data are switched lines only, which more accurately represents how Verizon-Virginia actually deploys ordinary loops.

39 Because the two versions treat non-direct cost differently (costs such as corporate overheads), I compare direct costs (costs associated with investment plus plant-specific maintenance expenses).

40 AT\&T/WorldCom's line count projection of 5.7 million lines for 2002 exceeds the FCC's actual 1998 line count of 4.1 million lines by over 38 percent.
} 
AT\&T/WorldCom instead reduce these rates relative to the FCC's, e.g., they decrease overall cost of capital from the FCC's 11.25 percent to 9.54 percent, with the overall effect being a 10 percent reduction in the direct loop cost (from $\$ 7.47$ to $\$ 6.75$ ) 41, which accounts for 14 percent of the total difference between the original and final direct loop costs. All other input changes reduce direct loop costs by an additional $\$ 1.61$ (from $\$ 6.75$ to $\$ 5.14$ ), or 31 percent of the total difference. Finally, AT\&T/WorldCom's changes to the Model reduce costs by an additional $\$ 0.51$, which is about 10 percent of the original difference.

\section{Conclusion}

During the same time that the Supreme Court had been deliberating on whether the FCC's rules for pricing unbundled network elements are consistent with the Telecommunications Act, the competing interests (as well as the FCC) were engaged in proceedings that have been debating how close they come to measuring the ILEC's economic costs. The rules base the costs on those of a hypothetical firm that serves the entirety of the incumbent's existing demand with all new facilities. While the FCC itself concedes that no incumbent's network actually resembles that of the hypothetical firm, its economic costs, and therefore the prices that would prevail under competition, would. ILECs, on the other hand, have argued that their costs would not be those of an unfettered new entrant, but instead would reflect the sequential business decisions they make when they sequentially decide to keep or replace specific parts of their networks.

The wide differences (e.g., an over three-fold difference in loop costs in the proposals of CLECs and ILECs) clearly indicate that the debate transcends mere academic interest. This paper has presented a framework for understanding the competing perspectives and has identified a number of factors that explain the quantitative differences that result. In particular, the ubiquitous replacement assumption, particularly the version that makes no accommodation to the existing network, ignores the economic costs imposed on a firm due to incomplete and/or nonexistent secondary market for its existing equipment, transactions costs from replacing existing equipment, and costs associated with possible incompatibilities between equipment of differing vintages. To the extent that such costs are faced by real-world firms, any cost model that ignores them will underestimate economic costs. Specific ways in which cost models may ignore such costs include (1) underestimating rates of depreciation and cost of capital, (2) underestimating the amounts of spare capacity needed to function efficiently, and (3) overly optimistic assumptions about the opportunities for sharing support structures and/or the availability of low-cost inputs, such as switching. In addition, by assuming that an "efficient firm" can configure its network to match a snapshot of demand at a particular instant, existing cost models may tend to overestimate the magnitude of scale economies that real firms can enjoy.

In light of the Supreme Court's approval of TELRIC, a most interesting and important question is whether the FCC will not only recognize that carriers are constrained by their

\footnotetext{
${ }^{41}$ In contrast, Verizon proposed a higher cost of capital of 12.95 percent, as well as higher depreciation rates. Verizon's rates would increase loop costs by about 15 percent (relative to the FCC's rates), in contrast to the 10 percent reduction produced by AT\&T/WorldCom's financial inputs.
} 
current facilities, but it and other regulators applying TELRIC will recognize that these constraints have a material impact on economic costs. Such recognition can then be reflected in some of the model design and input choices ${ }^{42}$ that have the potential to bring TELRIC costs closer to economic costs.

\section{$5 \quad$ References}

Allais, Maurice (1997) “An Outline of My Contributions to Economic Science”, December 9, 1988. Reprinted in American Economic Review, 87: 3-12.

Crew, Michael A. and Paul R. Kleindorfer (1992) "Economic Depreciation and the Regulated Firm”, Journal of Regulatory Economics, 4: 51-61.

David, Paul A. (1990) "The Dynamo and the Computer: An Historical Perspective on the Modern Productivity Paradox”, American Economic Review, 80: 355-361.

Emmerson, Richard (1999) "Cost Models: Comporting with Principles" in James Alleman and Eli Noam, eds., The New Investment Theory of Real Options and its Implications for Telecommunications Economics, Kluwer: Boston.

Federal Communications Commission (1996) Implementation of the Local Competition Provisions in the Telecommunications Act of 1996, CC Docket No. 96-98, First Report and Order, August 8 ("Local Competition Rules").

Federal Communications Commission (1998) Federal-State Joint Board on Universal Service, CC Docket No. 96-45, Fifth Report \& Order, October 28.

Federal Communications Commission (1999) Federal-State Joint Board on Universal Service, CC Docket No. 96-45, Tenth Report \& Order, November 2.

Federal Communications Commission and the United States (2001) Reply Brief for Petitioners in Verizon Communications, Inc., et al. v. Federal Communications Commission, et al., In the Supreme Court of the United States, July.

Federal Communications Commission (2002a) Joint Application by BellSouth Corporation, BellSouth Telecommunications, Inc., and BellSouth Long Distance, Inc. for Provision of In-Region, InterLATA Services In Georgia and Louisiana, CC Docket No. 0235, Memorandum Opinion and Order, May 15.

Federal Communications Commission (2002b) Trends in Telephone Service, May.

Hausman, Jerry (1997) "Valuing the Effect of Regulation on New Services in Telecommunications", Brookings Papers, Microeconomics: 1-38.

\footnotetext{
42 As the FCC (2002a) demonstrated when it described its freshly-upheld TELRIC standard to BellSouth.
} 
Kahn, Alfred E., Timothy J. Tardiff, and Dennis L. Weisman (1999) “The Telecommunications Act at Three Years: an Economic Evaluation of its Implementation by the Federal Communications Commission", Information Economics and Policy, 11: 319365.

Lehman, Dale E. and Dennis Weisman. (2000) The Telecommunications Act of 1996: The "Costs" of Managed Competition, Kluwer: Boston.

David M. Mandy (2000) “TELRIC Pricing with Vintage Capital”, Presented at the Rutgers University, Center for Research in Regulated Industries, Advanced Workshop in Regulation and Competition, $13^{\text {th }}$ Annual Western Conference, Monterey, California, July 6.

McDermott, Karl A. and Carl R. Peterson (2001) "The Efficiency of the Inefficient Firm Standard in Setting Access Charges", Presented at the Rutgers University, Center for Research in Regulated Industries, Advanced Workshop in Regulation and Competition, $20^{\text {th }}$ Annual Conference, Tamiment, Pennsylvania, May 24.

New York Public Service Commission (2002), Case 98-C-1357, Order on Unbundled Network Element Rates, January 28.

Pitkin, Brian (2001) Direct Testimony before the Federal Communications Commission, CC Docket Nos. 00-218, 00-249, 00-251, July 31.

Salinger, Michael A. (1999) "Lowering Prices with Tougher Regulation: Forward-Looking Costs, Depreciation, and the Telecommunications Act of 1996", in Michael A. Crew, ed., Regulation Under Increasing Competition, Kluwer, Boston.

Shelanski, Howard (2001) Direct Testimony before the Federal Communications Commission, CC Docket Nos. 00-218, 00-249, 00-251, July 31.

Supreme Court of the United States (2002) Verizon et al v. FCC et al., Case No. 0051, May 13.

Tardiff, Timothy J. (2001) "Valuing the Use of Incumbent Telecommunications Networks", Presented at the Rutgers University, Center for Research in Regulated Industries, Advanced Workshop in Regulation and Competition, $20^{\text {th }}$ Annual Conference, Tamiment, Pennsylvania, May 24.

United States Court of Appeals for the D.C. Circuit (2002) United States Telecom Association, et al. v. Federal Communications Commission, May 24.

United States Court of Appeals for the Eighth Circuit (2002) Iowa Utilities Board v. Federal Communications Commission, July 18.

Weisman, Dennis L. (2002) "Did the High Court Reach an Economic Low in Verizonv. FCC', Review of Network Economics, (this volume) 